\title{
XLVIII. A study of growing crystals by instantaneous photomicrography. (Contributions from the chemical laboratory of Harvard College)
}

\section{Professor Theodore William Richards \& Ebenezer Henry Archibald A.M.}

To cite this article: Professor Theodore William Richards \& Ebenezer Henry Archibald A.M. (1901) XLVIII. A study of growing crystals by instantaneous photomicrography. (Contributions from the chemical laboratory of Harvard College), Philosophical Magazine Series 6, 2:11, 488-500, DOI: $10.1080 / 14786440109462715$

To link to this article: http://dx.doi.org/10.1080/14786440109462715

曲 Published online: 08 Jun 2010.

Submit your article to this journal \ulcorner

Џ Article views: 2

View related articles $\sqsubset$ 
The extreme values of $x / V$ experimentally obtained were $x / \mathrm{V}=-10$ in series 3 and $x / \mathrm{V}=\cdot 16$ in series 4 . Hence the values $n_{0}=1.5 \times 10^{4}$ and $n_{0}=2 \cdot 4 \times 10^{4}$ are computed for these extremes. Recalling that $4 \times 10^{4}$ is the number of particles per cubic centim. inferred for complete saturation, and that $n_{0}$ is the number at the initial section of the condenser contiguous to the hard-rubber plug, where many ions must already have vanished by absorption, I hold the value of $n_{0}$ stated to be in reasonable accord with the theory sketched in $\$ \$ 6-8$, and throughout the course of the present papers.

Brown University, Providence, U.S.A.

XLVIII. A Study of Growing Crystals by Instantaneous Photomicrography. (Contributions from the Chemical Laboratory of Harrard College.) By Professor Theodone William Richards, of Harvard University, and Ebenezer Henry Archibald, A.M., 1851 Exhibition Scholar of Dalhousie Unizersity*.

[Plates VII.-IX.]

COUNTLESS observers have watched the growth of crystals under the microscope. As long ago as 1839 attempts were made to study also the birth of crystals, in order to determine in what manner the new phase makes its entrance into the system. With a microscope magnifying 600 diameters, Link $\uparrow$ thought he could detect the formation of minute globules at the moment of precipitation-globules which soon joined and assumed erystalline form. Schmidt $\ddagger$, Frankenheim $\S$, and especially $\dot{V}$ ogelsang $\|$, made similar observations some years later, and several more recent accounts of this phenomenon have appeared. Modern investigators have been more concerned with the speed of separation from supersaturated or supercooled liquids than with the form of the first separation $\%$.

* Reprinted from the Proceedings of the American Academy of Arts and Sciences, xxxvi. p. 341 (1901). From a separate impression communicated by the Authors.

+ Link, Pogg. Ann. xlvi. p. 258 (1839).

I Schmidt, Lieb. Ann. liii, p. 171 (1845).

\$ Frankenheim, Pogg. Ann. cxi. p. 1 (1860).

il Vogelsang, Die Krystalliten (Bonn, 1875). See Lehmann, Molecularphysik, i. p. 730 (1888).

I Gernez, Compt. Rend. xcv. p. 1278 (1882); Moore, Zeits. phys. Chem. xii. p. 545 (1893); Friedländer \& Tammann, ibid. xxiv. p. 152 (1897); Taumann, ibid. xxv. p. 441 ; xxvi. pp. 307, 367; xxviii. p. 96 ; Kuister, ibid. xxv. p. 480 ; xxvii. p. 222 ; Bogajavlensky, ibid. xxvii. p. 585 . 
Ostwald, in 1891, accepted the interpretation of these data, which assumes that crystallization is always * preceded by the separation of an initially liquid phase, consisting of a supersaturated solution of the former solvent in its former solutet.

This explanation is indeed a plausible one, and undoubtedly holds true in cases like those studied by Schmidt and Vogelsang, where a substance separates at a temperature not far below its melting-point, and often where a substance soluble in one liquid is precipitated by the addition of a consolute liquid in which the substance is insoluble. For examples, phenol always separates from aqueous solution in the form of a liquid, and manganous sulphate forms at first two liquid phases when alcohol is added to its aqueous solution. On the other hand, the separation of a high-melting salt like baric chloride from its solution in pure water is much less likely to take place in this way. The almixture of water necessary to lower a melting-point from $900^{\circ}$ io $25^{\circ}$ would be so large as to make the new phase, a solution of water in baric chloride, supersaturated to an improbable extent. Moreover, we have no evidence of the existence of vitreous baric chloride at low temperatures.

It has long been known that an exceedingly small particle of solid is capable of starting crystallization $\ddagger$-a fact which may not be wholly foreign to the present discussion.

In any case, the matter seemed worthy of further experimenting. Ostwald says:- "Die erste Bildung der Krystalle lässt sich bei Salılösungen und dergleichen microscopisch nicht verfolgen, weil gewöhnlich im Gesichtsfeide an einer bislang gleichförmigen Stelle plötzlich ein Krystallchen erscheint." While this is true as far as the human eye is concerned, instantaneous photography, an art unknown in Link's time, seemed peculiarly fitted for the unprejudiced recording of the circumstances attending the genesis of crystals. An atteript in this direction is described below.

The problem resolved itself into the taking of a number of successive instantaneous microphotographs of a suitable mixture at the point of crystallization. This problem presented some difficulties, however. In order to secure a sufficiently brief exposure, very great illumination is needed. The greater the magnifying power of the lenses of the microscopecamera, the more intense must be the source of light. The

* This is obviously not the case in crystallization of water or of a metal, in freezing. - EDs. Phil. Mag.

$\dagger$ Lehrbuch, i. p. 1039 (1891).

$\ddagger$ Ostwald, Zeits, phys. Chem. xxii. p. 289 (1897). 
difficulty is increased by the fact that most crystals are so transparent as to absorb but little light, and reflexion is possible only in certain directions. Hence it is hard to obtain a distinct image even in a strong light. Moreover, the machinery necessary for shifting the plates must be so frietionless in construction, and so firmly fixed, as to impart no vibration to the camera or the mobile subject of study.

These difficulties were at least partially overcome by two different arrangements; the first of which caused the successive impression of a bright image in a dark field, and the second registered dark images in a succession of bright fields Obviously the former was the nore economical as regards expenditure of sensitized film, and the more simple in execution ; for when the field is dark, successive images can be obtained by a very slight motion of either object or film, while, when the field is light, the whole previously exposed surface must be replaced by a fresh surface before each exposure.

The apparatus consisted of a good compound microscope fitted above with a vertical folding camera, which was supported by two massive steel pillars on the heavy stand. It was, in short, the regular photomicrographic outfit made by Bausch and Lomb. Between the microseope and camera, in a suitable light-tight box, was placed a revolving shutter, which allowed an exposure equal to one fifth of the time of its revolution. Thus, when the shutter made two revolutions in a second, the exposure was one tenth of a second. A Henrici hot-air motor, combined with speed-reducing donble pulleys, enabled the experimenter to use any rate of revolution desired. The rate was reasonably constant, but no atteinpt was made to make it absolutely so. The sensitive plate or gelatine film was held above in a suitable holder, which was put in the place of the ground-glass plate used for focussing just before each series of exposures.

In carrying out the first of the two methods, it was for nd more convenient to move the crystallizing solution than to move the photographic plate. For this purpose, the slide bearing the drop of liquid was attached by a wire to a point just below the centre of a segment provided above with sawteeth. The segment was moved gradually by the oscillating motion of a connecting-rod, fastened by a crank to the revolving shutter at one end and playing into the saw-teeth on the other. In order to make the motion certain, the stroke of the connecting-rod slightly exceeded the distance between the saw-teeth. The segment was suspended in such a way 
that its centre of gravity coincided with its point of support, and the friction of its bearings was so adjusted that it would move easily, and yet remain stationary during the return stroke. The distance through which the observed object was moved was easily varied by altering the relative lengths of the lever-arms; distances varying from one tenth to one fiftieth of a millimetre were usually used. 'The shutter was so arranged that during the exposure the segment and slide were at rest, the shift in position being effected during the four fifths of the revolution through which the shutter was closed. The accompanying diagram will make the arrangement clearer (see p. 492).

As a source of light any ordinary combination of incandescent electric lights proved to be inadequate. A good Auer von Welsbach light with a powerful reflector was more satisfactory, but the best results were obtained with the help of sunlight dirested by a suitably arranged mirror and condensed by reflectors and lenses. The chief, though not serious, difficulty of this arrangement was the great heat caused by the converging rays; a difficulty which was obviated partially by an absorbent screen in later experiments*.

The first photographs were taken by reflected light, the drop of solution being placed upon a ruby-coloured slide. As soon as the crystallization had begun upon one edge of this drop, the very sensitive plate was uncovered and the shutter and segment were set in motion. The exposure was stopped after fifteen or twenty revolutions, so as to avoid confusing superpositions. Even with the strongest light the images were very faint and unsatisfactory; it is not worth the space to reproduce them here.

Another mode of obtaining light images on a dark ground, applicable to all except the isometric system of crystals, is the use of polarized light $\uparrow$. A Nicol prism was placed in the barrel of the microscope, and another just below the stage. The main body of the light was thus intercepted by the crossed prisms, and only that which had been deflected by the crystalline structure was allowed to emerge. It is true that this method could not in all probability decide the chief point at issue; for the prenatal globular condition of crystals would probably bave no effect on polarized light. Definite optical structure is of course necessary to produce the required deflexion of the plane of polarization, and such definite

* Hutchins has shown that pure water is as good as a solution of alum for this purpose (Am. Journ: Sci. cxliji. p. 526, 1892).

+ This suggestion was kindly made by Professor E. C. Pickering. 


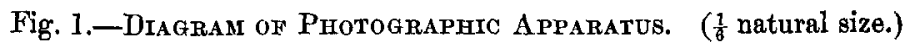

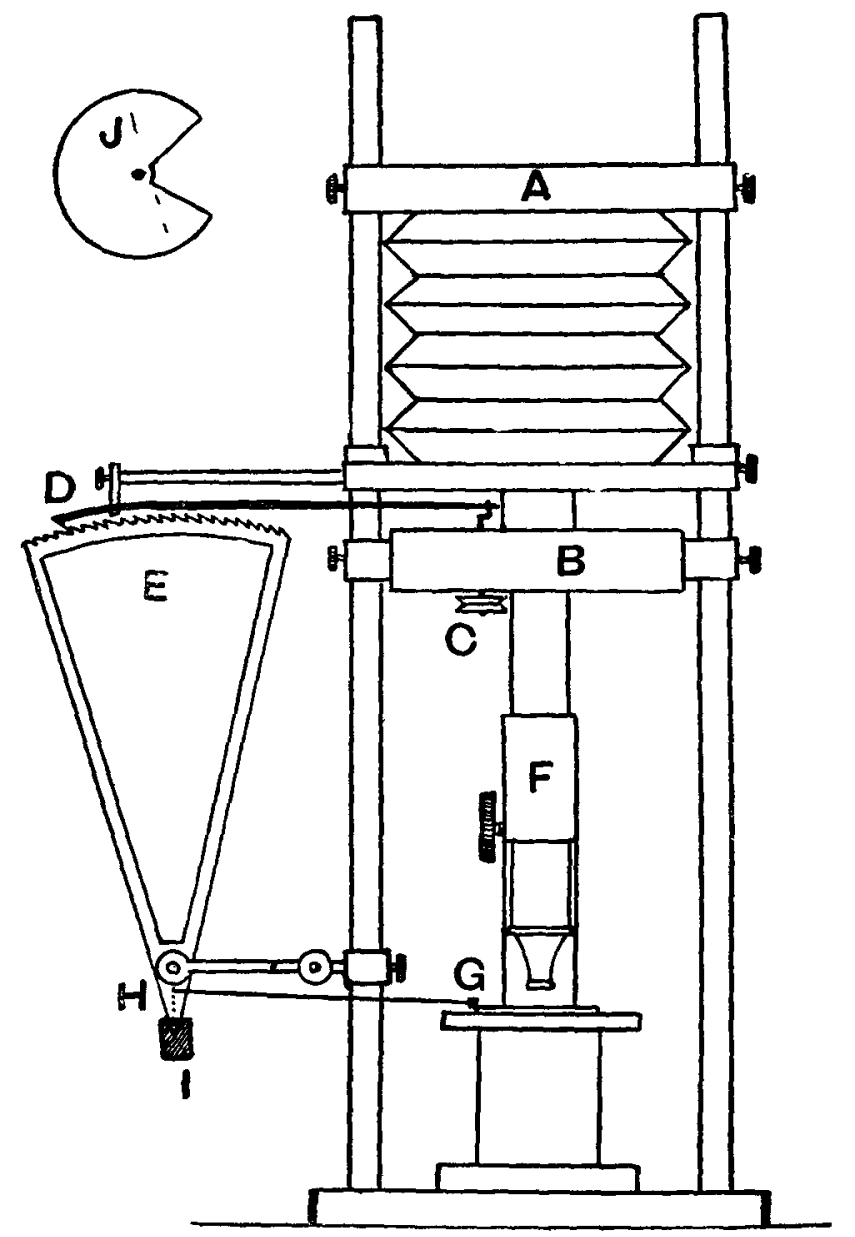

A, sensitive plate or film-holder.

$\mathrm{B}$, box containing shutter.

C, pulley attached to axle of shutter to communicate power from motor.

$D$, light rod mored by crank attached to same axle; $D$ is guided by a stout support in which it mores loosely.

E, segment provided with ratchet-teeth; moved gradually by rod D.

F, microscope.

$G$, slide for object, moved by wire running to $H$.

$\mathbf{H}$, holes to regulate amplitude of object's motion.

I, weight, balancing segment.

$\mathrm{J}$, horizontal projection of revolving shutter in detail.

The diagram represents the apparatus an instant before an exposure begins. 
structure might not be possessed by the globules. Nevertheless, the idea seemed well worth a trial.

The images were now much more clearly defined and striking, and with a magnification of 30 diameters, ten sharp impressions, each exposed $\frac{1}{50}$ second, could be obtained in a second. For this low power the eyepiece was removed from the microscope, and an objective with long focal distance alone was used to give the image. The degree of enlargement was obtained by actually measuring the image of a micrometer-scale divided into $\frac{1}{10}$ millimetres. The rapidity of exposure was so great that many plates were sacrificed, for it was difficult to find the precise moment when nascent erystals were in the field of view. In most cases the crystallization was already well started when the exposure began, as in fig. 4 ; but in some nothing but blank negatives were obtained. The best method is so to arrange circumstances as to have the crystallization begin upon one edge and spread slowly over the drop. Another difficulty was the attaining of the exact actinic focus, which differed slightly from the visual focus. It was found that a definite fraction of a revolution in the fine adjustment of the instrument, or a definite shift of the position of the sensitive plate, could be relied upon to cover this difference, when experiment had once found the right spot*.

Among other substances sodic nitrate, baric chloride, cupric sulphate, and ferrous ammonic sulphate were found to give satisfactory results. A few photographs chosen as being typical examples of many negatives are given here. (Plate VIII. figs. 2, 3, 4, 5.)

All the images recorded on these plates are perfectly sharp and regular when in focus; but the magnifying power was too low to give important evidence concerning the birth of the crystals. The crystals always first appear as points, indicating a diameter of less than $\frac{1}{300}$ millimetre. The regularity of growth of those already well started is worth a passing mention.

'The next objective used gave a magnification of' 110 diameters. With this power the light was so much diminished th at exposures of less than $\frac{1}{15}$ second became too pale. Three examples from among these negatives are given here. It $n$ ill be noticed that in all cases the crystals have their regular forms when they first appear upon the plate. Another point worthy of attention is the fact that the growth in diameter at first is more rapid than it seems to be subsequently. This

* Of course the use of an apochromatic lens would have saved us from this minor difficulty; but our method of worling accomplished the object with less expense. 


\section{Prof. Richards and Mr. Archibald : A Study of}

rapid growth of small particles has already been noticed by Ostwald*; it is treated more fully in the following pages. The crystals of sodic nitrate grew faster than those of baric chloride or cupric sulphate, and the two latter substances evidently appeared at first in very thin plates. It is interest. ing to note that the thickening of these plates caused a corresponding change in the quality of the emerging light, and hence the crystal-images show a rhythm of dark and light. (Plate VII. figs. 6 and 7, Plate ViII. fig. 9.)

At this point the whole method of procedure was changed on account of the probability that a globular condition, if it existed at all, would not be visible through the crossed Nicols. The apparatus was now arranged for the exposure of successive portions of a film to unpolarized sunlight emanating from a bright field, upon which the crystals appeared as dark spots. The slide and crystallizing solution were allowed to remain stationary, and the gelatine film was moved, as it is in the common film-cameras. The $2 \frac{1}{2}$-inch Eastman cartridge film was found to answer the purpose. At first the turning was effected by an automatic electromagnetic arrangement which received its current from a make-and-break contact attached to the shntter. Since a current of ten amperes was needed to secure a sufficiently forcible and speedy action, the operation of this derice was somewhat troublesome, and when the exposures were not much more frequent than one a second the film was rolled by hand. A suitable signal attached to the shutter axle, which was still turned by the Henrici motor, gave the necessary indication of the proper moment for renewing the sensitive surface. With this apparatus it was of course possible to obtain photographs of isometric crystals, which could not be examined with the preceding arrangement.

At first a power of 100 diameters was employed, and very satisfactory pictures of the growth of crystals of potassic iodide were obtained. One of these negatives is reproduced here as an example. (PlateVIII. fig. 9.) They showed nothing new, however ; hence a much higher power of 580 diameters was applied by combining a " 2 -inch" eyepiece with an " $\frac{1}{8}$-inch" objective. With this contrivance the light was of course far less intense, and the definition less sharp. Even with the brightest sunlight, concentrated by mirrors and an Abbe condenser, the exposure could not profitably be made less than $\frac{1}{8}$ second. These plates have been enlarged by usual processes to over seven times their original size, so that a total enlargement of over four thousand diameters has been

* Ostwald, Zeits. phys. Chem. xxii. p. 320 . 
attained. Since these larger images are not much more clear than the smaller ones, while they occupy much more space, the plates herewith given are all from the original negatives.

A number of good impressions of crystallizing potassic iodide were taken under these circumstances, but many other rolls were sacrificed. The chief difficulty, as before, was to secure the right moment; and this difficulty was of course much angmented by the limited expanse of the tield. Prints from a few of the successful negatives are given below. In order to give a clear impression in printer's ink, these were much intensified by successive photographic printing and intensification; but of course no attempt was made to remove the imperfections of the successive plate's, for which allowance may easily be made. (Plate IX. figs. 10-15.)

T'he study of these photographs reveals several interesting points. In the first place, it is noticeable that no image is wholly without evidence of crystalline structure. The most doubtful cases are those in figs. 9 and 11 ; but the elongated shape of these doubtful images seems to indicate a solid. A globule of a new liquid phase, $\frac{1}{1000}$ millimetre in diameter, would have left an unmistakably circnlar image on the highly magnified plate, for its index of refraction could not have been identical with that of the aqueous solution. The fact that we could not find such a globule of course does not prove that a globule cannot exist, either for an infinitesimally brief period of time, or of an infinitesimal magnitude beyond the reach of microscopic observation. Nevertheless, so many scores of photographs were taken as to diminish considerably the probability that such globules can ever be seen with substances possessing a high melting-point.

A striking fact to be noticed in nearly all the most highly magnified records is the ill-defined appearance of the smallest crystals. This appears to be due, not to a lack of structure, but rather to the rapid growth in diameter which is manifest in the young crystal. 'The initial rapidity is so great that the fifth of a second appears to include several different stages of growth, and hence a blurred impression results. It is easy to obtain some idea of the rapidity of this initial growth by comparing the sizes of the first two or three appearances of each crystal.

With this object a few of the series were measured by means of an accurate micrometer; but the conditions of the experiments are too uncertain to give the very precise measurements much value. Perfect constancy of temperature and evaporation, as well as in the rate of the revolving shutter, involving grave complications in the apparatus, 
496 Prof. Richards and Mr. Archibald : A Study of

should of course be maintained if great accuracy is attempted. Measurements with a fine millimetre-scale afford all the precision which it is worth while to attain under present conditions. A typical case (fig. 9, largest crystal) gave the following measurements in millimetres for the successive longest diameters:-2.0; $2 \cdot 6 ; 3 \cdot 0 ; 3 \cdot 2 ; 3 \cdot 3 ; 3.5 ; 3.7$; $3.9 ; 4 \cdot 1 ; 4 \cdot 2 ; 4 \cdot 4$. The actual sizes of the crystals were of course only a hundredth of these measurements, since the enlargement was 100 diameters.

In spite of the inexact nature of such measurements, it is possible to use them as a means of defining approximately the law regulating the changes in speed. The following table details six series of corresponding diametric measurements of six crystals taken at random. The measurements were taken directly from the photographs, in millimetres.

Diameters of Successive Images.

\begin{tabular}{|c|c|c|c|c|c|c|}
\hline & $\begin{array}{c}\text { Crystal } \\
1 .\end{array}$ & 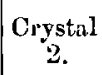 & $\begin{array}{c}\text { Crystal } \\
3 .\end{array}$ & $\begin{array}{c}\text { Crystal } \\
4 .\end{array}$ & $\begin{array}{c}\text { Crystal } \\
5 .\end{array}$ & $\begin{array}{c}\text { Crystal } \\
6 .\end{array}$ \\
\hline First appearance...$\ldots \ldots$ & $1 \cdot 0$ & 20 & 30 & $3 \cdot 0$ & $4 \cdot 0$ & 25 \\
\hline Second appearance ...... & $1 \cdot 6$ & 26 & $5 \cdot 7$ & 60 & 67 & 35 \\
\hline Third appearance......... & $1 \cdot 7$ & $3 \cdot 0$ & $6 \cdot 8$ & 70 & $7 \cdot 8$ & $4 \cdot 1$ \\
\hline
\end{tabular}

These all show greater growth in the first interval than in the second. In order to reduce them to one standard, the diameter of the third appearance was taken in each case as unity. The table then becomes :-

Diameters of Successive Images.

\begin{tabular}{|c|c|c|c|c|c|c|c|}
\hline & $\begin{array}{c}\text { Orystal } \\
1 .\end{array}$ & $\begin{array}{c}\text { Crystal } \\
2 .\end{array}$ & $\begin{array}{c}\text { Crystal } \\
3 .\end{array}$ & $\begin{array}{c}\text { Crystal } \\
4 .\end{array}$ & $\begin{array}{c}\text { Crystal } \\
\bar{\Xi} .\end{array}$ & $\left\{\begin{array}{c}\text { Crystal } \\
6 .\end{array}\right.$ & A verage \\
\hline First appearance ... & 0.59 & 067 & $0 \cdot 44$ & $0 \cdot 43$ & $0 \cdot \tilde{1} 1$ & $0 \cdot 61$ & $0 \cdot 54$ \\
\hline Second appearance & 0.94 & $0 \cdot 87$ & 0.81 & $0 \cdot 86$ & $0-86$ & $0-85$ & 0.87 \\
\hline Third appearance... & $1 \cdot 00$ & 100 & $1 \cdot 00$ & $1 \cdot 00$ & $1 \cdot 00$ & $1 \cdot 00$ & $1 \cdot 00$ \\
\hline
\end{tabular}

At the time of the first appearance, the average age of the crystal must be about half the time intervening between two exposures ; for the crystal must have been formed since the last exposure, and it is as likely to come near the beginning as near the end of the interval. Thus in fig. 11 the erystals 
evidently started immediately after the previous exposure, while in fig. 9 they were registered while still very young. The averaging of a much larger number of observed diameters led to the slightly different values given below, corresponding to the accompanying times :-

\begin{tabular}{|c|l|}
\hline Time $=t$. & Diameter $=$ D. \\
\hline 0 interral & Diameter 0 \\
0.50 interval & Diameter 0.57 \\
1.50 intervals & Diameter 0.87 \\
2.50 intervals & Diameter 1.00 \\
\hline
\end{tabular}

These data are plotted in fig. 16 (see p. 498).

The inspection of the figure shows at once that the curre is similar in general shape to one represented by the equation $\mathrm{D}^{n}=k t$, where $\mathrm{D}$ is the diameter of the crystal, $t$ the time from the birth of the crystal, and $k$ a constant. The only question is as to the magnitude of $n$. The curves which result from the assumptions $n=2$ and $n=3$ are given in the figure, for comparison with the experimental curve. It is clear that the curve with the latter value, $n=3$, is the nearest, possessing the same general curvature, and deviating from the average less than the individual measurements do. This is equivalent to saying that equal increments of time correspond to equal increments of volume, instead of equal increments of surface, as one might have supposed. Of course a law based upon such merely approximate data cannot be considered as definitely settled; but clearly the general character or telldency of the curve is established. It is probable that under the necessarily ill-defined conditions of our experiments the growth follows no one law with precision ; supersaturation, convection, diffusion, and evaporation must all influence the result. The crystal which seems to have deviated most widely from the average is that depicted in fig. 10 ; this crystal grew at first less rapidly than usual, and finally came almost to a standstill. It is possible that an increasing solubility due to increasing temperature may have caused this delaying tendency.

It is interesting to compare this average, calculated on the assumption that the crystal starts in the middle of the dark interval, with a few single cases which appear to have begun to crystallize very near the beginning or end of the interval. In these cases, the first image of the crystal will appear 
498 Prof. Richards and Mr. Archibald : A Study of

Fig. 16.--Diagram mepresheting Rate of Increasfin ingstal. DIAMETER.

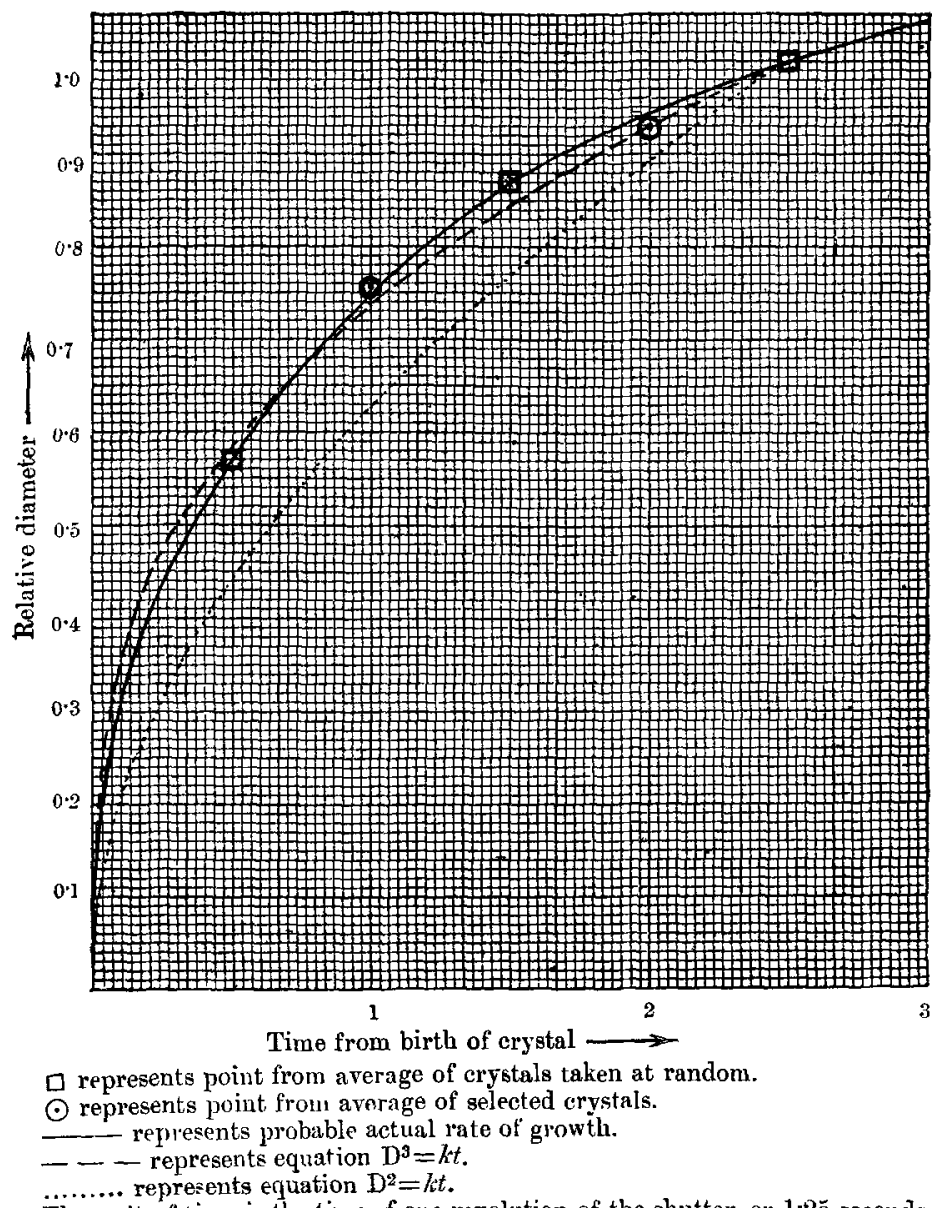

The unit of time is the time of one revolution of the shutter, or 1.25 seconds. The substance was potassic iodide.

either almost as large as the second image, or very small compared with it. It will appear almost as large as the second image when the preceding exposure has just not caught the beginning of the crystal, which has thus had a whole interval for growth; or very much smaller than the second image when the first impression has registered a crystal only a very small fraction of a second old. Marked examples of the former case are to be found in fig. 11, and of the latter in the largest crystal in fig. 9, and the smallest 
crystal in fig. 15. The times of revolution represented by figs. 9 and 11 are the same, 1.25 seconds, and the other conditions also were identical, hence we may compare these with accuracy. Careful measurements of the sizes in fig. 9 showed the first large impression of the crystals to be about eighty per cent. of the diameter of the next impression, and approximately the same relationship appears in fig. 11 . In order to find if this relationship corresponds with the equation $\mathrm{D}^{3}=h t$, the larger diameter is assumed to be 0.93 , the theoretical value corresponding to two intervals of tine, if that corresponding to two and one half intervals is taken as unity. Hence the smaller one becomes 0.75 , corresponding to one interval of time; a value, marked in a circle on the diagram, which is surprisingly near the cubic curve. Hence the equation $D^{3}=k t$ is confirmed. That the same curve holds approximately for the further growth of the crystal is manifest by a quantitative study of tig. 9 (Plate VIII.).

In this connexion it is interesting to note that the crystal seems often to grow at first in the sime proportion in all directions. Even the very minute image in the centre of the second exposure, given in fig. 9, shows itself under the microscope to be elongated like the crystal which grows from it. In the next exposure this crystal had the proportions $0.02 \mathrm{~mm}$. $\times 0.0125 \mathrm{~mm}$, and after four more exposures it still had almost exactly the same proportions, being $0.035 \mathrm{~mm}$. $\times 0.022 \mathrm{~mm}$. After two or three more seconds the form given in fig. 9 began to change slightly, the crystal becoming slightly less elongated in shape; but by this time the neighbouring crystals had grown so much as to approach it, and hence to alter the conditions. A similar constaney in proportion may be observed in many other series here given.

The diagram shows how exceedingly fast the diametric growth of the crystal must be in the first tenth of a second of its existence. Hence we have an explanation for the suddenness of its appearance to the eye of an observer, and for the blurred edges of its photographic image. It is true that another cause may contribute to the blurred effect; namely, the irregular refraction caused by the convection of the lighter solution which has just deposited part of its load; but the speedy growth alone is capable of explaining the observed indistinctness.

Interesting as the rapid initial yrowth in diameter may be, it places a serious bar in the way of more precise study of the birth of crystals. One clearly needs not only high magnifying power, but also great speed; and these two together require 
very intense light. Whether or not we shall be able to obtain more positive knowlerge with the present apparatus, is a questionable matter. In the near future the attempt will be made here to carry further the work herein described; but it is doubtful if any more definite results will be obtained. The great speed of initial growth casts a measure of doubt over some of the observations of Link and his followers. Is is not possible that the suljective effect of the rapidly growing crystal might be mistaken for that of a globule of liquid? Even upon the photographic plate there is a slight resemblance, and in one or two cases deliberate stady is needed to detect evidence of structure in the smallest crystals.

In conclusion, the report of the foregoing pages may be summarized as follows:- It bas been found possible to take very frequent photomicrographs of crystals during their birth and growth. An enlargement of over four thousand diameters was obtained, and both common and polarized light were used. Only substances with high melting-points were examined, and the crystallization was always from aqueous solution. No properly focussed image on any of the plates seemed to be devoid of crystalline structure. "The growth in diameter during the first second of the crgstal's life was found to be vastly greater than during the subsequent period. Not the diameter itself, but a power of the diameter, was proportional to the time under the conditions used in our experiments. This exceedingly rapid initial diametric growth accounts for a lack of definition noticed in the first images,a lack of definition sufficient to have misled the eye, but not enough wholly to obscure the photographic evidence of crystalline structure.

Hence we may conclude that whatever theoretical reason there may be for believing that crystals always develop from a transitory liquid phase, the present experimental evidence is inadequate to prove that these globules attain a size visible in the microscope, except in the case of substances which melt at temperatures not far from the temperature of crystallization. The present paper is to be regarded rather as the suggestion of a mode of study than as a finished treatment of the subject, however.

The apparatus might be used to obtain a series of kinetoscopic pictures of insects or other small animals or plants, and is now heing used for the study of the change in structure of steel at high temperatures. We are indebted to the Rumford Fund of the American Academy of Arts and Sciences for some of our apparatus.

Cambridge, Mass., October 1898 to October 1900. 
Phil. Mag. S. 6. Vol. 2. Pl. VII.
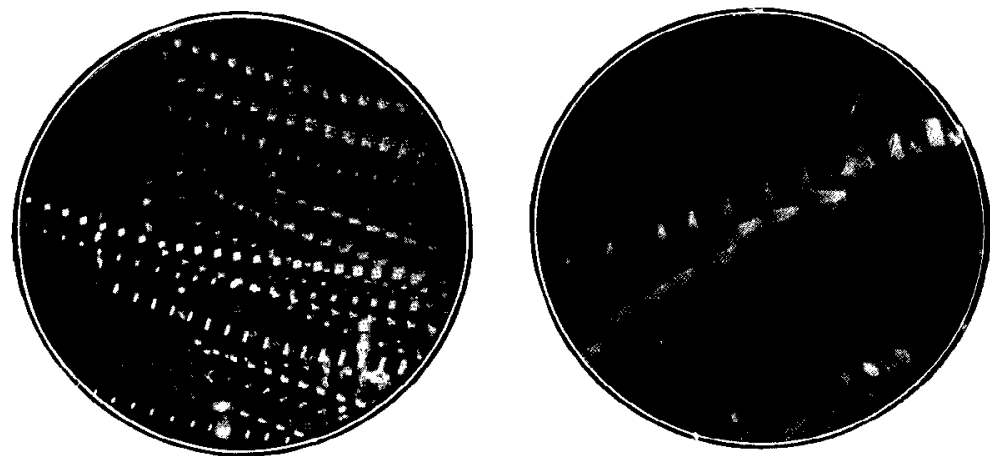

Ftatre 2. Baric chloride; 30 diam.: exposure 0.04 sec.

Fig URe 3. Baric chloride; 30 diam. ; exposure 0.08 sec.

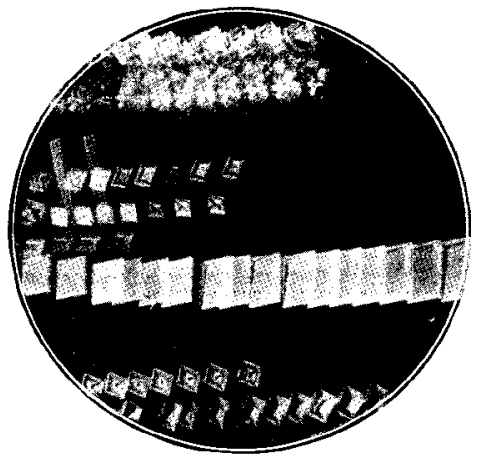

Figure 4. Sodic nitrate; 30 diam. ; exposure $0 \cdot 10$ sec.

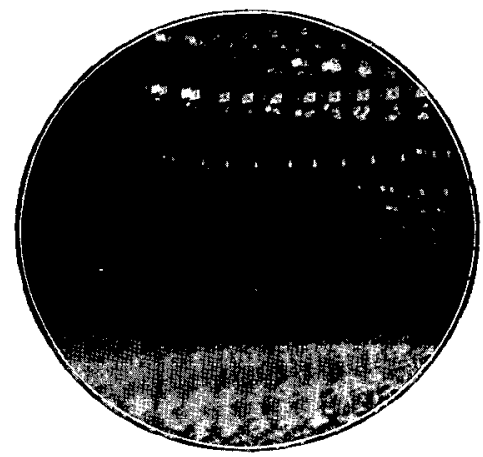

Frgure 5. Sodic nitrate; 30 diam.; exposure 0.12 sec.

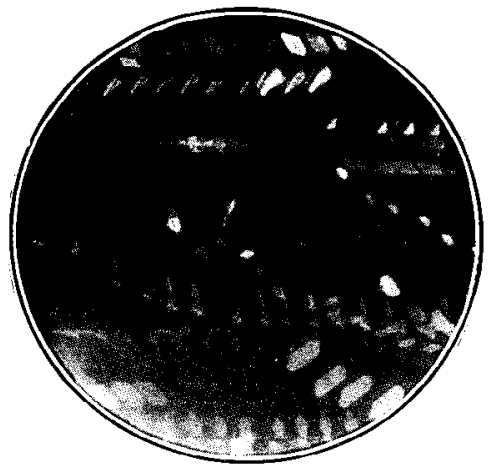

Figdre 6. Baric chloride; 110 diam.; exposure $0 \cdot 10$ sec.

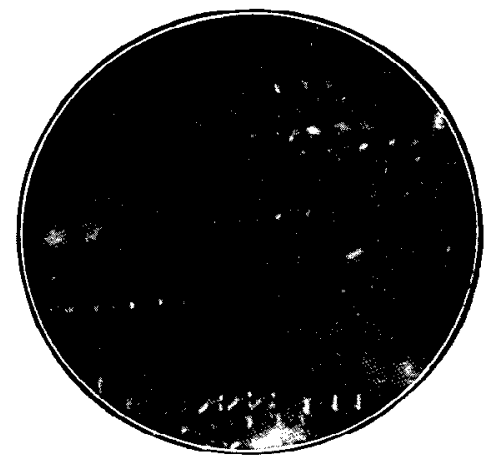

Figure 7. Cupric sulphate; 110 diam.; exposure $0 \cdot 12$ sec. 
Phil. Mag. S. 6. Vol. 2. Pl. VIII.

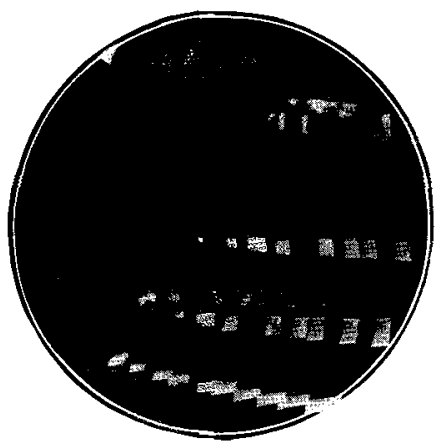

FIGUre 8 Sodic nitrate; 110 diam.; exposure 0.12 sec.

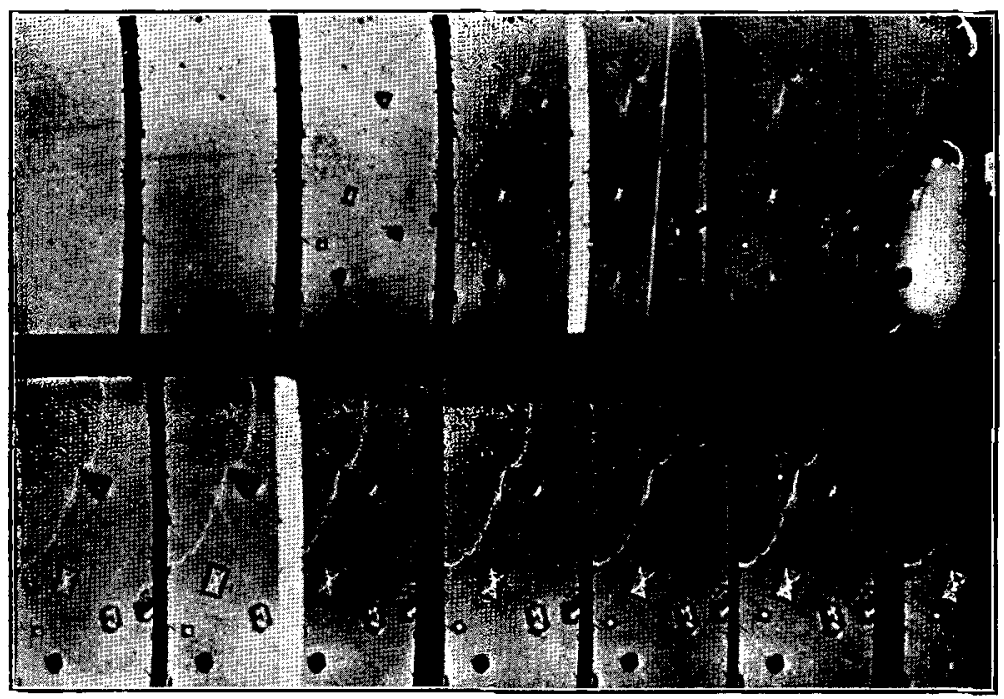

Figure 9. Potassic iodide; 100 diam.; exposure 0.25 sec. 
Phil. Mag. S. 6. Vol. 2. Pl. IX.
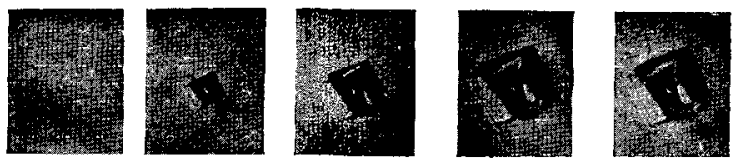

Figure 10. Potassic iodide; 580 diam.; exposure 0.17 sec.

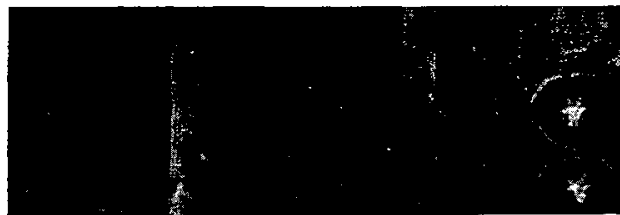

Figure 11. Potassic iodide; 580 diam. ; exposure 025 sec.
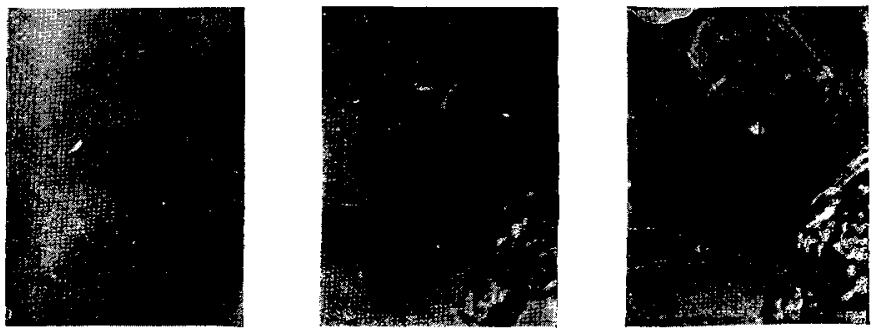

Figure 12. Potassic iodide; 580 diam.; exposure 0.17 sec.
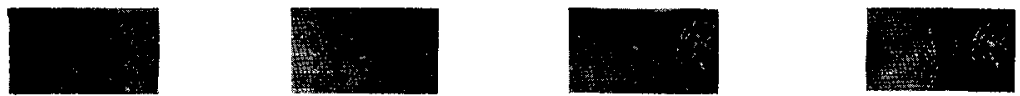

Fiaune 13. Potassic iodide; 580 diam. ; exposure 017 sec.
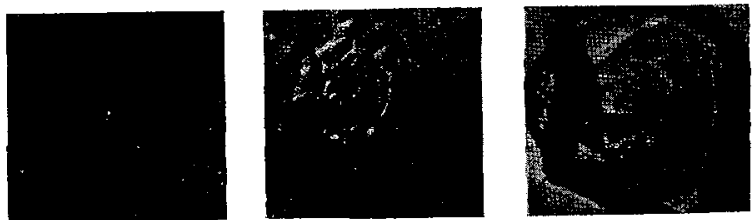

Figure 14. Potassic iodide; 580 diam.; exposure 0.17 sec.
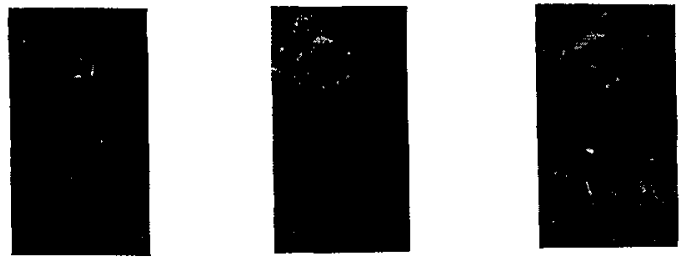

FigUR: 15. Potassie iodide; 580 diam.; exposure $0 \cdot 17$ sec. 